\title{
Cuffed Hemodialysis Catheter
}

National Cancer Institute

\section{Source}

National Cancer Institute. Cuffed Hemodialysis Catheter. NCI Thesaurus. Code C122618.

A hollow tube that is inserted into a large vein to carry blood to and from a dialysis

machine where the exit site is secured just under the skin with a band-like structure to prevent slippage and infection. 